$\begin{array}{llll}\sum_{\text {Louise Lannefors }} & \square & \text { Respiratory Medicine and } & \text { Respiratory Medicine and } \\ & \begin{array}{l}\text { Allergology, Lund University } \\ \text { Hospital, Lund, Sweden }\end{array} & \begin{array}{l}\text { Allergology, Lund University } \\ \text { Hospital, 22185 Lund, } \\ \end{array} & \text { Sweden }\end{array}$

\title{
Physical training: vital for survival and quality of life in cystic fibrosis
}

\section{Educational aims}

$\odot$ To understand the current standard of care for cystic fibrosis patients.

- To appreciate the benefits of incorporating physical activity into patient care.

$\odot$ To explain how physical activity can be incorporated into individual patients' programmes.

\section{Summary}

Cystic fibrosis is a progressive, genetic disease requiring multidisciplinary care. Treatment is symptomatic, but increasingly preventative rather than reactive. Physical activity is becoming part of the standard of care and appears equally as efficacious as traditional methods, and is time efficient with numerous studies demonstrating clinical benefit.

Cystic fibrosis (CF) is a progressive, autosomally inherited, multi-organ system disease that requires qualified care by a multidisciplinary team [1-3]. Many patients suffer from voluminous pulmonary hypersecretion with chronic airway infection and inflammation, which, without adequate treatment, cause pulmonary cysts, bronchiectasis and fibrosis that sooner or later lead to lethal respiratory insufficiency. The cause of death in CF is respiratory insufficiency in $\sim 85 \%$. Continuous problems, such as poor nutritional status and suboptimal treatment in general, influence the course. CF used to be a paediatric disease, but nowadays patients survive well into adulthood and have the opportunity to live a life with good quality $[1,4] .10$ years ago, the mean annual mortality rate in the Swedish CF population from 1991 was $0.9 \%$ for females and males (fig. 1) [5]. The corresponding median age at death during this period was 26 years (fig. 1) [5]. Due to the fact that fewer CF patients die early in life, making long-time survival estimates is increasingly difficult. According to a Kaplan-Meier analysis, the predicted survival in the Swedish population born during the 1990 s was estimated at $95 \%$ reaching $\geqslant 25$ years of age (fig. 2) [5]. In that study, $75 \%$ of all Swedish CF adults who had finished educational studies were working and
Statement of interest None declared.

HERMES syllabus link: modules A.13, B.15.1, 1.4 


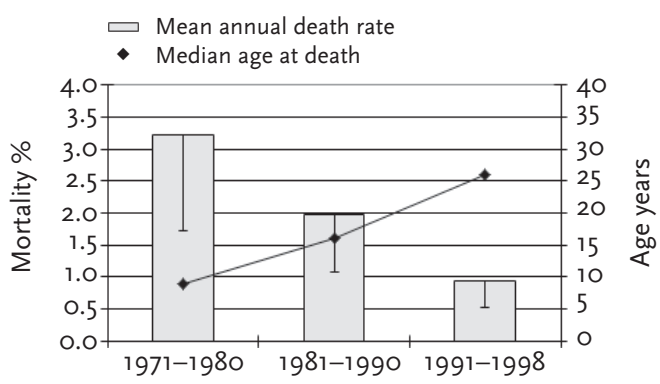

Figure 1

Mean $\pm S D$ annual mortality rate and median age at death in the Swedish cystic fibrosis population [5].

$22 \%$ had children [5]. To be able to manage all the activities of daily life, they benefit from being in good physical condition. However, published reports claim that musculoskeletal complications, such as thoracic kyphosis and mechanical back pain, appear with increasing age and/or decreasing lung function, as does the incidence of osteoporosis, vertebral wedging and fractures $[6,7]$.

CF still cannot be cured. The treatment offered is symptomatic, although nowadays preventive rather than reactive. Each individual must be offered a daily treatment that, although time consuming, can actually be adhered to. Prescribing or recommending a daily CF treatment package is like a jigsaw puzzle. One of the cornerstones in the treatment package is physiotherapy. Until the beginning of the 1980s, physiotherapy in CF included only clearance of mucus from airways and, basically, only one airway clearance technique was available at the time: postural drainage with percussion and vibration (PD+PV) in combination with forced expirations (huffing). The airway clearance therapy was passive, time consuming and boring for the patient, always requiring an assistant to

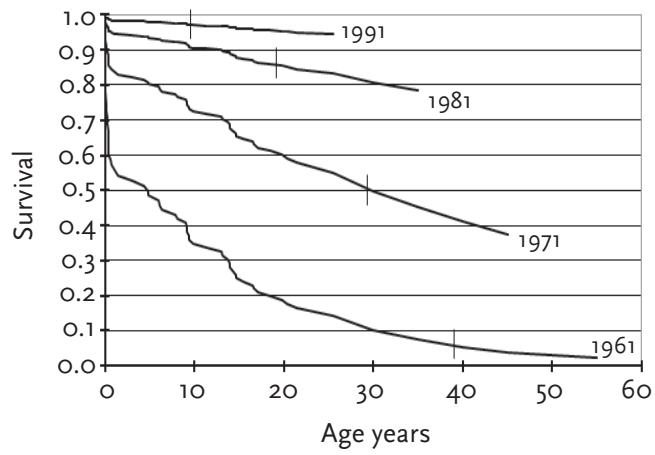

Figure 2

Current and estimated survival rates of four different cohorts of Swedish cystic fibrosis patients [5]. Vertical ticks indicate estimates and years indicate patient birth date. be performed. Simultaneously, patients were recommended not to strain themselves; children were recommended to refrain from physical education at school simply due to the coughing it caused. PD+PV with huffing is still being used for all ages in many parts of the world, but more often it is presented as the only possible technique for children $<5$ years of age, although without huffing. Since the mid-1980s, more airway clearance techniques have been developed [8]. However, until about a decade ago, there were patients who were encouraged to be inactive due to early chronic infection/lung function deterioration. Due to staying at home and bed rest during repeated hospital stays, skeletal muscle weakness and exercise intolerance were prevalent in CF $[7,9]$.

Physical activity and sports in general, and physical exercise are increasingly more commonly used as part of the European Cystic Fibrosis Society (ECFS) standards of care [10, 11]. However, the aim of physical exercise in CF is still most often defined as improving working capacity. Most studies have been concerned merely with rehabilitation, evaluating the effects of physical exercise after short, intensive intervention periods, from 2 weeks to a few months, away from daily life surroundings and routines [12]. The results are often impressive, but to what extent patients can preserve the achieved exercise level is not discussed. It should be at least as important to assess to what extent patients can retain the effects of training, especially given that long-term studies have reported that physical exercise reduces the rate of lung function deterioration [13-15].

Lund CF Centre (Lund, Sweden) is responsible for the care of all patients living in the south of Sweden. Since the beginning of the 1980 s, physiotherapy at the centre has included inhalation therapy, airway clearance therapy and physical activity/sports/exercise [16]. The airway clearance therapy has been based upon physical exercise and interspersed with huffing, in accordance with the results of an 18-month study performed at the centre in 1980-1983 [17]. The study showed equally good results as with PD + PV and huffing, but patients refused to return to the old technique. Since 1983, PD+PV has not been used at all in the Swedish CF centres, not even in infants and young children, for whom physical exercise has been interspersed with gentle thoracic compressions or assisted autogenic drainage (fig. 3) $[16,18]$. As patients 


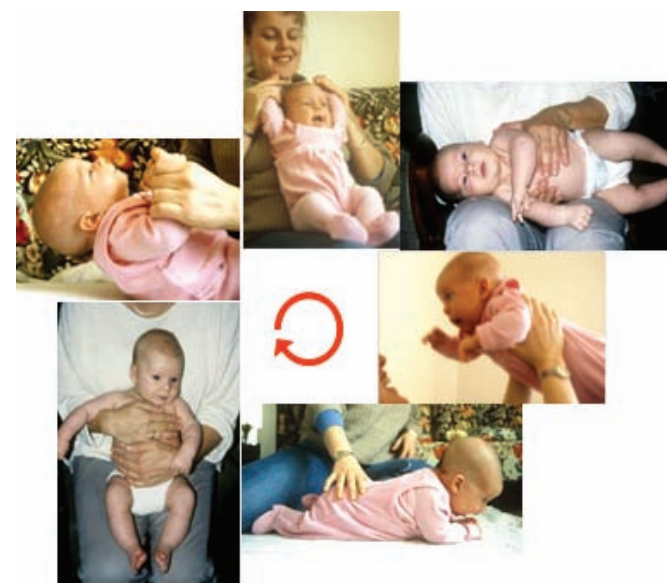

Figure 3

Airway clearance therapy based on physical exercise combined with assisted autogenic drainage, performed in an infant.

grow into their teens and older, airway clearance may be performed with the help of another modern technique or a combination of techniques that fit the individual patient for the moment. Sports and a few physical exercises at least a couple of times each week are then added to the airway clearance therapy for the otherwise physically active patient. However, there is nothing to suggest that all airway clearance therapy sessions during the day or week must be the same.

The airway clearance technique based upon physical exercise is time efficient, since two parts of the physiotherapy regime are actually performed at the same time. The rationale of the airway clearance therapy is the effect of the "respiratory pump", with increased minute ventilation, larger tidal volume, changed functional residual capacity and/or an irregular breathing pattern. It is the immediate respiratory physiological effects that are used as the basis of airway clearance therapy (step 1 in fig. 4). The respiratory pump can be utilised even further when exercises are carried out in horizontal, rather than erect, positions, since gravity influences regional ventilation distribution and regional functional residual capacity differently in horizontal positions $[15,19]$. The fact that gravity has effects on mucus clearance during airway clearance therapy has been confirmed, although a study has shown that while lying on their side, most patients had better clearance effect in the dependent lung [19]. Physical exercise is combined with the forced expiration technique or autogenic drainage at different lung volume levels (steps 2 and 3 in fig. 4) in the cycle

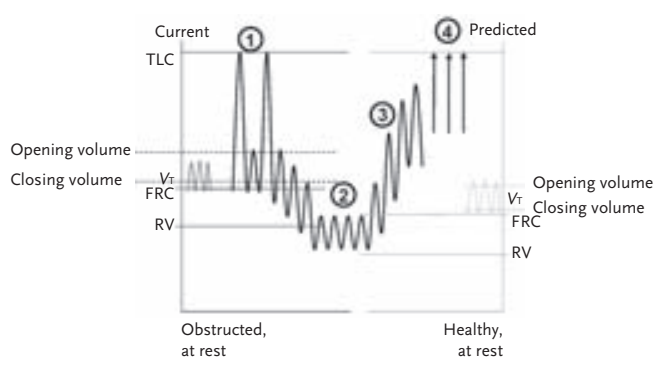

Figure 4

The physiological airway clearance treatment strategy illustrated schematically. The four numbered steps are included in a cycle that is repeated over and over again. TLC: total lung capacity; VT: tidal volume; FRC: functional residual capacity; RV: residual volume.

which is repeated over and over again during the airway clearance therapy [8, 15]. The physical exercise includes not only working capacity training as soon as possible due to age, but also training of mobility and muscle strength. Maintained chest wall mobility, both inspiratory and expiratory, is a prerequisite for effective airway clearance therapy; being able to reduce the residual volume to as low a level as possible during airway clearance therapy (step 2 in fig. 4), it allows loosening and mobilisation of mucus from peripheral airways in as many parts of the lungs as possible. While using physical exercise as a basis for airway clearance therapy, preservation of a good working capacity, healthy posture, good chest wall mobility and muscle strength will occur simultaneously over the long term [20]. Other advantages of physical exercise as the basis for airway clearance therapy are that it is easy to adapt to the current situation and it does not necessarily require any devices. It certainly has specific aims for the patients but also allows siblings, friends and parents to participate. The physical exercise performed is easily adapted to many factors that may make it optimal and continuously interesting. The choice of activities and exercises is only limited by the physiotherapists imagination.

Modern physiotherapy should be performed in a preventive rather than a rehabilitative manner, aiming at not only building up but also preserving overall physical function and maintaining quality of life (QoL). All Swedish CF patients $\geqslant 7$ years of age are subject to expanded national testing where a lung capacity test always is performed at the clinical physiology laboratory. In a national study where data were collected from an annual test, the lung function expressed as

\section{Educational questions}

1) What does modern physiotherapy in CF care include?

a. Airway clearance therapy and working capacity training

b. Inhalation

therapy and airway

clearance therapy

c. Airway clearance therapy, inhalation therapy and physical exercise

2) What does physical exercise in CF care included?

a. Working capacity rehabilitation, mobility and strengthening exercise

b. Working capacity training, preventive mobility and muscle strengthening

exercises

c. Working capacity training and muscle strengthening exercises

3) What factors are necessary to consider for CF patients to preserve good BMD?

a. Calcium intake from childhood

b. D-vitamin supplementation added to calcium intake and preventive, weight-bearing physical exercise

c. Physical exercise, calcium intake and

D-vitamin

supplementation 
Table 1 Mean lung function in all Swedish cystic fibrosis patients $\geqslant 7$ years of age in two age groups

\begin{tabular}{|c|c|c|}
\hline & \multicolumn{2}{|c|}{ Age } \\
\hline & 7-17 years & $\geqslant 18$ years \\
\hline Subjects \% & 48 & 52 \\
\hline $\mathrm{FEV}_{1} \%$ pred & 90 & 73 \\
\hline VC \% pred & 96 & 91 \\
\hline \multicolumn{3}{|c|}{$\begin{array}{l}F E V_{1} \text { : forced expiratory volume in } 1 \mathrm{~s} ; \% \text { pred: \% } \\
\text { predicted; VC: vital capacity. Data from [14]. }\end{array}$} \\
\hline
\end{tabular}

forced expiratory volume in $1 \mathrm{~S}\left(\mathrm{FEV}_{1}\right)$ and vital capacity (VC) was reported to be very good in both children and adults (table 1) [15]. The expanded annual tests also involve a standardised peak working capacity test on a bicycle ergometer performed at the clinical physiology laboratory. Data collected from three out of the four CF centres, showed a mean peak working capacity of $100 \%$ predicted in the 7-17-years age group and $90 \%$ in the $\geqslant 18$-years group [20]. With a preserved good working capacity, patients may participate in physically demanding events and live an ordinary life with good QoL. The same is true if or when the lung disease progresses and the physical exercise is being performed with oxygen supplementation (fig. 5). The same study showed that the group with $\mathrm{FEV}_{1}<50 \%$ pred had a mean peak working capacity of $75 \%$ [20]. Attempting to maintain posture and bone mass density (BMD) aims to prevent complications such as chronic musculoskeletal pain and fractures. The adult population at the Lund CF Centre has experienced very little postural degeneration and musculoskeletal pain. BMD measurement using dual-energy X-ray

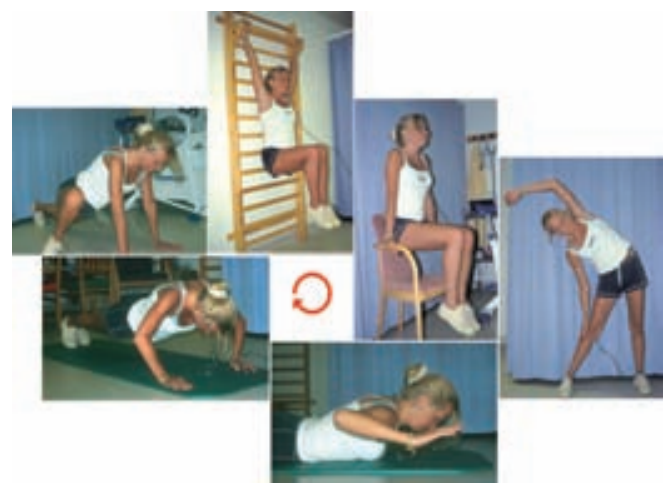

Figure 5

A severely ill patient (forced expiratory volume in $1 \mathrm{~s}$ $\sim 25 \%$ predicted) performing physical exercise with supplementary oxygen, while on the list for lung transplantation.

absorptiometry showed only one osteoporotic individual and none with vertebral fractures [21].

A few years ago, $59 \%$ of all German CF centres responded to a questionnaire about current exercise practices [22]. Overall, 60\% of the responding centres had performed exercise testing about once per 2.3 patientyears for patients $\geqslant 8$ years of age, but only $42 \%$ of the tests carried out were performed according to standardised protocols. Of the responding centres, only $31 \%$ included exercise tests in the annual routine and only $27 \%$ organised a training programme [22]. In a more recent study, only $38.9 \%$ of paediatric and $27.8 \%$ of adult patients in UK CF centres had performed an exercise test in the preceding 12 months, and only $26 \%$ of the clinics provided exercise training programmes [23]. The ECFS has a task force dealing with recommendations on performance of regular working capacity tests; their result will soon be available. Another project is to revise ECFS standards of care, in which physical activity/sports/exercise as a part of the basic treatment package will most probably be highlighted.

References

1. Davies JC, Alton EW, Bush A. Cystic Fibrosis. Br Med J 2007; 335: 1255-1259.

2. Yankaskas JR, Marshall BC, Sufian B, et al. Cystic Fibrosis adult care. Chest 2004; 125: 1S-39S.

3. Taylor-Robinson D. Health inequalities and cystic fibrosis. BMJ 2011; 343: d4818.
4. Yuksel H, Yilmaz O. A new model for cystic fibrosis management: control concept. Pneumonia 2011; 60: 150-154.

5. Lannefors L, Lindgren A. Demographic transition of the Swedish Cystic Fibrosis community - results of modern care. Respir Med 2002; 96: 681-685. 
6. Elkin SL, Fairney A, Burnett S, et al. Vertebral deformities and low bone mineral density in adults with cystic fibrosis: a cross-sectional study. Osteoporos Int 2001; 12: 366-372.

7. Botton E, Saraux A, Laselve $\mathrm{H}$, et al. Musculoskeletal manifestations in cystic fibrosis. Joint Bone Spine 2003; 70: 327-335.

8. International Physiotherapy Group for CF. Physiotherapy in the treatment of CF, IPG-CF Blue Booklet 2009. www.cfww.org/ipg-cf/article/195/ Physiotherapy_in_the_Treatment_of_CF

9. Troosters T, Langer D, Vrijsen B, et al. Skeletal muscle weakness, exercise intolerance and physical activity in adults with cystic fibrosis. Eur Respir $J$ 2009; 33: 99-106.

10. Dwyer TJ, Elkins MR, Bye PT. The role of exercise in maintaining health in cystic fibrosis. Curr Opin Pulm Med 2011; 17: 455-460.

11. Kerem E, Conway S, Elborn S, et al. Standards of care for patients with cystic fibrosis: a European consensus. J Cyst Fibros 2005; 4: 7-26.

12. Gruber W, Orenstein DM, Braumann KM, et al. Health-related fitness and trainability in children with cystic fibrosis. Pediatr Pulmonol 2008; 43: 953-964.

13. Moorcroft AJ, Dodd ME, Morris J, et al. Individualised unsupervised exercise training in adults with cystic fibrosis: a 1 year randomised controlled trial. Thorax 2004; 59: 1074-1080.

14. Pianosi P, LeBlanc J, Almudevar A. Peak oxygen uptake and mortality in children with cystic fibrosis. Thorax 2005; 60: 50-54.
15. Dennersten U, Lannefors L, Höglund P, et al. Lung function in the ageing Swedish cystic fibrosis population. Respir Med 2009; 103: 1076-1082.

16. Lannefors L, Button B, Mcllwaine M. Physiotherapy in infants and young children with cystic fibrosis: current practice and future developments. J R Soc Med 2004; 97: 8-25.

17. Andreasson B, Jonson B, Kornfält R, et al. Long-term effects of physical exercise on working capacity and pulmonary function in cystic fibrosis. Acta Paediatr Scand 1987; 76: 70-75.

18. Van Ginderdeuren F, Malfroot A, Verdonck J. Influence of assisted autogenic drainage (AAD) and AAD combined with bouncing on gastro-oesophageal reflux (GOR) in infants under the age of 5 months. J Cyst Fibrosis 2003; 2: Suppl. 1, A251.

19. Lannefors L, Wollmer P. Mucus clearance with three chest physiotherapy regimes in cystic fibrosis: a comparison between postural drainage, PEP and physical exercise. Eur Respir J 1992; 5: 748-753.

20. Lannefors L, Dennersten U, Ortfelt M, et al. Patients with cystic fibrosis can preserve peak working capacity, even if lung function is substantially impaired. J Cyst Fibros 2010; 9: Suppl. 1, A33.

21. Lannefors L, Neglén P, Hellberg K, et al. Only a few osteoporotic adult CF patients and no vertebral fractures. J Cyst Fibros 2008; 7: Suppl. 2, 72.

22. Barker M, Hebestreit A, Gruber W, et al. Exercise testing and training in German CF centres. Pediatr Pumonol 2004; 37: 351-355.

23. Stevens D, Oades PJ, Armstrong N, et al. A survey of exercise testing and training in UK cystic fibrosis clinics. J Cyst Fibros 2010; 9: 302-306. 